\title{
A Dialética da Modernização Conservadora e a Nova História do Brasil*
}

José Maurício Domingues

\section{A DIALÉTICA DA MODERNIZAÇÃO}

passagem das diversas formações sociais para a modernidade
tem sido desde sempre um problema a chamar a atenção dos ci-
entistas sociais, consistindo, de resto, em um tema formativo para a
própria sociologia. Marx, Weber e Durkheim, assim como a teoria da
modernização e as alternativas a ela que a partir do marxismo se apre-
sentaram, todos emprestaram centralidade a essa questão. No Brasil,
uma ampla literatura a esse respeito foi articulada, uma vez que, na
verdade, ele tem sido crucial para o desenho da própria identidade
do país, nesse sentido reproduzindo questão que se põe em coordena-
das mais gerais através do mundo. Em particular, a história parecia
crucial para que se pudesse dar conta do presente do país, pois a ex-
plicação e a correção de seus descaminhos eram percebidas como ra-
dicando em uma precisa identificação de seus processos - e taras -
formativos. Oliveira Vianna e Nestor Duarte, Sérgio Buarque de Ho-
landa e Gilberto Freyre, Caio Prado Jr. e Raymundo Faoro, entre tan-
tos outros, debruçaram-se, assim, sobre nosso passado colonial e

* Agradeço a Luiz Werneck Vianna e a Adalberto Cardoso os comentários sobre versões anteriores deste artigo.

DADOS - Revista de Ciências Sociais, Rio de Janeiro, Vol. 45, nํ3, 2002, pp. 459 a 482. 
pós-independência, buscando identificar aqueles elementos que acabariam por moldar nossa passagem para a modernidade.

Uma das teorias mais bem-sucedidas na tentativa de analisar essas transições para a modernidade, seja nos países centrais em que esta se originou seja nos periféricos, que apenas de forma derivada foram empurrados para o mundo moderno, foi elaborada por Barrington Moore Jr. (1966). Nessa abordagem, as vias socialista revolucionária, democrática e autoritária foram identificadas como três possíveis caminhos de chegada à modernidade. Esse foi um livro de grande impacto no Brasil. Em especial, a última das três vias para a modernidade parecia se encaixar perfeitamente com nossa trajetória. Em Moore Jr., o grande exemplo do que chamou de "modernização conservadora" era dado pelos Junkers alemães, que durante bastante tempo conseguiram controlar a transição para o mundo moderno sem deixar de contemplá-la e inclusive estimulá-la, sobretudo no que tange à industrialização, mas sem perder tampouco o controle do campo e mantendo suas propriedades oriundas do período feudal. No Brasil, os grandes proprietários agrários, que surgiram no período mesmo de formação da Colônia e, deslocamentos não obstante, continuaram preeminentes e poderosos durante o Império e a República, espelhavam aqueles agentes originais da modernização conservadora. Reis (1982) estudou-a durante o período do café, na República Velha, ao passo que Werneck Vianna (1976) se concentrou no período pós-1930, aproximando o conceito de Moore Jr. daquele que em Lenin definia uma "via prussiana" para o capitalismo, com referência exatamente ao caso alemão.

De forma resumida, pode-se compreender o conceito de "modernização conservadora" a partir das seguintes coordenadas. Primeiramente, a recusa a mudanças fundamentais na propriedade da terra. Os grandes proprietários manteriam, destarte, controle também sobre a força de trabalho rural, que não seria capaz, portanto, de se libertar de relações de subordinação pessoal e de extração do "excedente" econômico por meios mais diretos. Foi isso que teve lugar na Alemanha e no Brasil, ao contrário, por exemplo, do que se passou na Inglaterra, com a transição para uma mercantilização do trabalho agrícola, ou na França e no México, com a revolução camponesa levando ao fim ou ao menos a um profundo enfraquecimento da grande propriedade rural e ao parcelamento da terra. Na modernização conservadora, as tradicionais elites agrárias forçaram uma burguesia relutante e avessa aos 
processos de democratização a um compromisso: a modernização fazia-se, sob a liderança e levando muito em conta os interesses dos proprietários agrários, conformando-se uma "subjetividade coletiva" centrada em um bloco transformista, cauteloso e autoritário em suas perspectivas e estratégias.

No Brasil, a inelasticidade e o controle da fronteira agrária foram cruciais para a subordinação das massas rurais. Por outro lado, abria-se espaço para a industrialização e uma certa migração, cada vez mais acentuada, do campo para a cidade. $O$ baixo custo da força de trabalho podia ser garantido, contudo, pelas limitações da fronteira agrícola ${ }^{1}$ e pelo controle político que se exercia sobre a classe trabalhadora, mormente sobre o sindicalismo, o que se deu no Brasil com recurso ao corporativismo estatal, de inspiração fascista. De modo geral, pode-se dizer que a modernidade era paulatinamente implantada entre nós de modo a impedir que um de seus elementos fundamentais, a liberdade, ganhasse muito espaço. Era sobretudo fundamental minimizar os processos de "desencaixe" que operavam nos planos individual e coletivo, liberando a força de trabalho, conferindo cidadania, desvinculando os sujeitos da subordinação e da vida presa a contextos específicos e fixos, reconfigurando o espaço-tempo social que agora se tornava mais amplo, nacional, e agudamente orientado para o futuro - a modernização-, e prenhe, por conseguinte, de possibilidades de mudança de vida (ver Domingues, 2002, esp. caps. 2 e 4). Se imperava o que se chamou de "cidadania regulada" nesse período (Santos, 1979), por outro lado, uma "tradição republicana", que buscava mediar a incorporação progressiva das massas que emergiam para a vida livre e para a política, foi um dos elementos que se destacaram nesse processo (Werneck Vianna, 1991). Especialmente esta última não compôs um projeto claro e articulado, levado a cabo por uma "subjetividade coletiva" organizada, com identidade distinta e com forte intencionalidade, mas emergiu sim como resultado de respostas que, a partir de tradições políticas herdadas (ponto que elaborarei abaixo), vários agentes buscavam ante a modernização marcada por extrema exclusão que esteve em curso ao longo do século passado.

Entretanto, uma dialética virtuosa forçou seu caminho no curso da modernização conservadora. A incansável modernização do país, sobretudo ao longo do século XX, implicou transformações de largo alcance. Em particular aqueles processos de desencaixe alcançaram proporções radicais em solo brasileiro, ensejando mais liberdade e 
autonomia para os indivíduos e coletividades que jamais anteriormente. O sucesso do programa de modernização conservadoramente dirigido minou as próprias bases do conservadorismo à medida que emergia um país cada vez mais moderno, com indivíduos e subjetividades coletivas mais livres, menos propensos a ser manipulados. As duas ditaduras que marcaram o século XX brasileiro foram expressão das dificuldades dos núcleos dirigentes da modernização conservadora em controlar esse processo. Durante a segunda delas, que abarca o período de 1964 a 1986, este parece se ter, todavia, esgotado. A modernização havia ido tão longe que não era mais possível manter o controle sobre as novas subjetividades coletivas modernas e "desencaixadas" que se consolidaram durante a vigência da ditadura militar. Um estudioso do país refletiu desta forma a respeito do esgotamento do processo, do ponto de vista dos interesses e das instituições políticas ${ }^{2}$ :

“Em outras palavras, a essência da crise institucional contemporânea define-se pelo fato de que o processo político real deixou para trás, e muito longe, as instituições criadas há cinqüenta anos. O corporativismo subdesenvolvido está em crise porque não consegue conter mais encapsulado o processo nominal de competição entre os diversos segmentos sociais. Ao mesmo tempo, ainda não se desenham com clareza os marcos institucionais que irão balizar a evolução histórica futura" (Santos, 1993:37).

O mesmo poderia ser dito sobre o que se passa no plano das escolhas pessoais, do que se poderia chamar de "política da vida", das opções sexuais, religiosas, da situação da mulher e dos jovens etc. Mesmo que em meio a profundas desigualdades sociais, o grau de liberdade nessas áreas aumentou de maneira exponencial e a pluralidade das formas de vida que caracteriza a modernidade brasileira contemporânea é extremamente ampla (ver Domingues, 1999a, cap. 1; 1999b, caps. 5 e 7). Um relevante pluralismo societário foi paulatinamente se aprofundando.

No que concerne à própria tese da modernização conservadora, há uma série de dados que podem ajudar a visualizar melhor a monta das transformações pelas quais o país passou ao longo do século XX. A mais óbvia é a que se refere à distribuição da população, com uma importância acentuada das grandes cidades e uma urbanização em todo caso avassaladora. Segundo Garcia e Palmeira (2001:41, 64 e ss.), 
baseados em dados do IBGE, a população urbana teria passado de $70 \%$ em 1980 para $78 \%$ em 2000, culminando o que caracterizou aquele século brasileiro como um generalizado processo de "desruralização" (termo que colhem em Sachs). Não se trata de supor que a população rural desaparecerá; isto é, não é o caso de aceitar simplesmente que a ruralidade estaria destinada à erradicação. Na verdade, essa questão não está sequer em pauta aqui. Mas até mesmo aqueles que, como Veiga, se opõem a essa tese e afirmam a continuada importância do Brasil rural, admitem que, segundo dados do censo de 2000 do IBGE interpretados de modo muito e espantosamente diferente do que aquele dos autores citados acima, cerca de $60 \%$ da população do país viveria em cidades. Isto precisaria, segundo esse autor, ser qualificado pela constatação de que, dos municípios considerados, aqueles "indiscutivelmente urbanos" tiveram seu peso populacional relativo acrescido, entre os censos de 1991 e 2000 , de $54,6 \%$ para $56,8 \%$, ao passo que o peso dos municípios "essencialmente rurais" caiu de $32,5 \%$ para $30,4 \%$, com aqueles "relativamente rurais" mantendo seu peso estável, próximo a 13\%. Nos "municípios mais atraentes do Brasil rural", a população teria aumentado mais de $30 \%$, enquanto crescia 20\% no Brasil urbano, e 15\% no conjunto do país (Veiga, 2001:101). Embora Veiga argumente contra a idéia de um "êxodo" rural, que só se teria mantido no "âmbito dos três estados sulinos" (idem:102), seu uso dos dados do IBGE, de todo modo, indica claramente que aumentou o grau de urbanização do país e que boa parte da população rural deixou de habitar o campo propriamente dito, mesmo se ainda vive em suas cercanias urbanizadas. Se isto não significa abandono das atividades agrícolas - embora mesmo isso deva ser qualificado por elementos que serão introduzidos abaixo, referentes ao tipo de ocupação não-agropecuária dessa população rural-urbana -, não haveria como deixar de reconhecer que relações de subordinação pessoal e o controle dos trabalhadores pelos grandes proprietários de terra, na verdade, não têm como se reproduzir nessas novas condições ${ }^{3}$.

Extraídos diretamente da página do IBGE na internet, os dados abaixo atestam que, quaisquer que sejam as variações possíveis na interpretação do fenômeno, e sem entrar em detalhes acerca da diferenciação entre diversos tipos de município tal qual proposta por Veiga, ou pretender contestá-la, é altíssimo o nível de urbanização do país com todas as conseqüências sociais e políticas que se pode disso deduzir. Deve-se notar que, mesmo em um espaço de vinte anos apenas, 
Gráfico 1

Brasil - População

Por Situação do Domicílio (\%)

\begin{tabular}{l|c|c|c|c}
\hline População & 1980 & 1990 & 1996 & 2000 \\
\hline Urbana & 67,59 & 75,59 & 78,36 & 81,25 \\
Rural & 32,41 & 24,41 & 21,64 & 18,75 \\
\hline
\end{tabular}

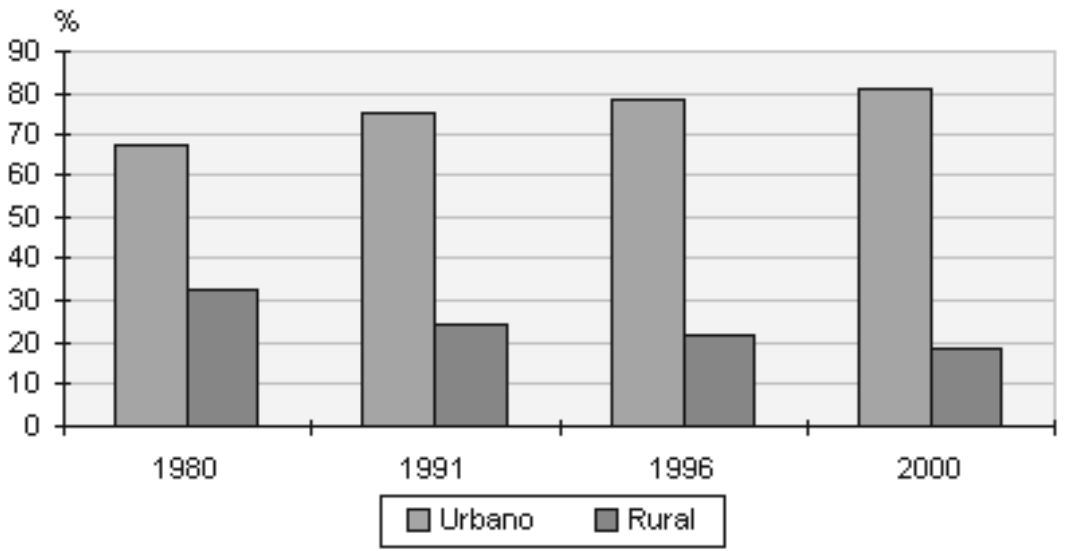

Fontes: Brasil em Síntese, Instituto Brasileiro de Geografia e Estatística, Censo Demográfico (1980; 1991; 2000) e Contagem da População (1996) (www.ibge.gov.br).

e no curso de duas décadas de difícil e parco desenvolvimento econômico, há um acréscimo de quase $14 \%$ da população urbana, que em 2000 totalizava $81,25 \%$.

Ainda segundo dados do IBGE, a população ocupada, em termos de distribuição nos diversos ramos de atividade, inclui menos de um quarto dos trabalhadores no setor agrícola, como se vê no Gráfico 2.É complicado desagregar esses números, sendo preciso considerá-los de acordo com sua diferenciação interna, buscando especificar em que medida a rubrica serviços não inclui trabalho relacionado ao setor agrícola, e até que ponto a rubrica trabalho agrícola não inclui serviços de fato não diretamente relacionados a tarefas típicas do campo. Argumentos que caminham nessa direção logo serão apresentados a partir da leitura de especialistas no tema. Grosso modo, contudo, esses dados apontam também para a perda de influência dos setores agrários, econômica e socialmente. 


\section{Gráfico 2}

Brasil - População

Pessoas Ocupadas por Ramos de Atividade

\begin{tabular}{l|c|c|c|c}
\hline $\begin{array}{l}\text { Ramos de } \\
\text { Atividade }\end{array}$ & 1996 & 1997 & 1998 & 1999 \\
\hline Agrícola & 16.541 .298 & 16.770 .675 & 16.338 .100 & 17.372 .105 \\
Indústria & 13.515 .818 & 13.864 .789 & 14.072 .164 & 13.804 .961 \\
Comércio & 9.071 .119 & 9.222 .789 & 9.416 .999 & 9.618 .374 \\
Serviços & 28.792 .552 & 29.473 .254 & 30.135 .850 & 30.880 .779 \\
\hline
\end{tabular}

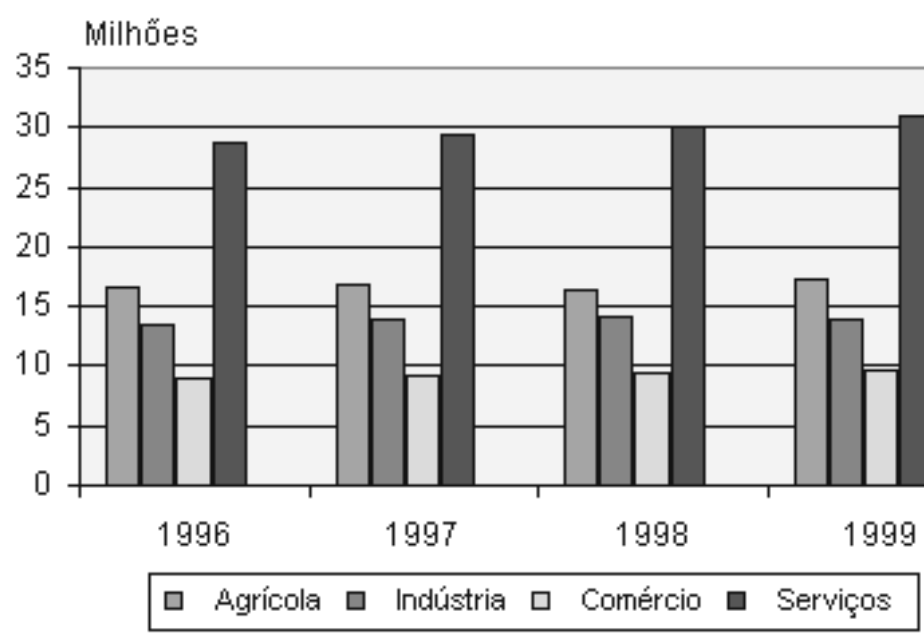

Fonte: Brasil em Síntese, Instituto Brasileiro de Geografia e Estatística, Pesquisa Nacional por Amostra de Domicílios (1999) (www.ibge.gov.br).

As próprias características e o sucesso de uma iniciativa como o Movimento dos Trabalhadores Rurais sem Terra - MST falam a favor da tese do fim da modernização conservadora no que tange a seus elementos centrais: ele caracteriza-se como um movimento que congrega proletários, bóias-frias, em suma, “[...] milhares de famílias rurais pobres que vagam pelos campos brasileiros, à procura de ocupação e renda e, também parte dos assalariados rurais [...]"; em outras palavras, compõe-se dos rebentos do novo padrão de relações sociais que vige na agricultura brasileira hoje, ainda que incorpore também pequenos proprietários, posseiros e arrendatários (Navarro, 2002a:195). 
A isso se soma, por um lado, o fechamento da fronteira agrícola e de terras "livres" - desde sempre, aliás, como observado acima, problemáticas na história brasileira - e a redução das formas de ocupação agrícola, em virtude dos impasses e saturação, ao menos no curto prazo, da produção agrícola, o que gera uma larga "população sobrante" que se agrega ao MST. De certa forma, não é absurdo propor a tese de que o MST somente tem a força e desfruta de extrema mobilidade espacial hoje porque os trabalhadores rurais - ora sem terra - não se encontram submetidos ao arbítrio pessoal e às formas tradicionais de mandonismo dos grandes proprietários agrários. Os dados do Censo Agrário do IBGE, de 1996, indicam, em particular, um reduzido número de arrendatários, parceiros e ocupantes no Brasil de hoje: 268.294 arrendatários, ocupando 8.649.002 hectares; 277.518 parceiros, ocupando 3.174.527 hectares; 709.710 ocupantes, totalizando 10.132 .826 hectares; contra 3.604.343 proprietários, que ocupam um total de 331.654 .891 hectares $^{4}$.

Por outro lado, constata-se igualmente que grande número de atividades não agrícolas determina, crescentemente, a "dinâmica das ocupações nas áreas rurais do país", com as atividades agrícolas (amiúde de baixa qualificação) respondendo cada vez menos, inclusive, pelo sustento de famílias de pequenos proprietários: a agropecuária é fonte de apenas $32 \%$ da renda de famílias rurais de assalariados e de $45 \%$ da de famílias rurais formadas por pessoas que trabalham por conta própria ou de quem é empregador (Graziano da Silva, 2001:39-43; Veiga, 2001:102; Navarro, 2002b:273). Isso contrasta com o declínio acentuado do poder e da influência dos grandes proprietários, que empobreceram e perderam também sua força política, o que se expressa, por exemplo, em sua incapacidade de garantir políticas públicas e esquemas de financiamento favoráveis, bem como no virtual desaparecimento da União Democrática Ruralista - UDR, sem prejuízo da manutenção em larga escala da concentração fundiária no país, mas com forte inclinação outrossim favorável ao agrobusiness "globalizado" (Navarro, 2002b:272; Delgado, 2001).

Assim, as relações de subordinação pessoal e de controle da força de trabalho que imperavam no período anterior se desfizeram e um vasto processo de "desencaixe" teve lugar, com um "reencaixe" coletivo desses trabalhadores constituindo novas subjetividades coletivas, como cidadãos e proletários, acompanhando a dissolução daquela situação anterior. Isso não quer dizer que não haja sobrevivências no imaginário popular de um tipo de cristianismo messiânico para o 
qual a posse da terra continuaria a ser fundamental. Tampouco se deveria supor que os grandes proprietários de terra não teriam logrado sobreviver, quando, na verdade, muitos conseguiram uma conversão a um capitalismo modernizado no campo e, por vezes mesmo, à agroindústria, perpetuando certa influência política que deriva de seu poder tradicional, de sua riqueza e de seu peso social (Garcia e Palmeira, 2001). Em suma, tanto do ponto de vista econômico quanto do político, o que se poderia chamar de "revolução passiva" (que não é o mesmo que a "modernização conservadora", conquanto se possa dizer que esta foi uma forma de aquela se realizar durante longo período) se mantém vigente, com adaptações "transformistas" dos velhos agentes à nova ordem. Isto é verdadeiro quanto a esse ponto específico como ainda no que se refere aos processos mais amplos de modernização do Estado e de sua direção, com, enfim, a paulatina assunção de hegemonia e domínio por "elites" com origem em São Paulo e nível variado de vínculo com a burguesia paulista, que cumpriu um papel relativamente subordinado nas coalizões que se efetivaram no pós-1930. Esses personagens assumem a linha de frente e a direção dos processos de modernização ora em curso sem que tenha havido, entretanto, uma ruptura do processo político e a perda do controle por parte do bloco dominante, ainda que este se tenha reconfigurado em larga medida (ver Werneck Vianna, 1996). Uma breve consulta às candidaturas e coalizões, no período que se seguiu ao fim do regime militar e à redemocratização, clara e progressivamente demonstraria essa mudança de padrão, seja com relação ao Partido dos Trabalhadores - PT, seja no que se refere ao Partido da Social-Democracia Brasileira - PSDB e, de modo geral, às forças que sustentam as principais candidaturas nos sucessivos pleitos desde 1989. Isto não obstante a vitória de Collor naquele fatídico ano - devendo-se notar, em contrapartida, que seu governo redundou em rematado fracasso e no impeachment.

Se esses dados por si sós não dizem do quanto se tem, de fato, uma libertação da população do controle exercido pelos "coronéis" e pelas oligarquias locais (no modelo classicamente desenhado por Leal, 1976), convém sublinhar que as teorias da sociologia política sugerem que mudanças políticas associadas à urbanização e a transformações das estruturas socioeconômicas dos municípios devem estar em curso nesse sentido (Soares, 2001), estando ligadas à industrialização ou, amiúde neste caso, à agroindústria e à expansão do setor urbano de 
serviços que gravita em torno às áreas predominantemente rurais. Segundo mapas geoeleitorais (ver Romero et alii, 2000), que confrontam níveis de desenvolvimento econômico e social, e de urbanização, com dados das eleições majoritárias, de 1989, 1994 e 1998, é exatamente nas regiões mais atrasadas, mais rurais, onde grassa o analfabetismo e se encontram baixos níveis de "IDH" (o Índice de Desenvolvimento Humano, da Organização das Nações Unidas), que os partidos conservadores se alicerçam. Mas esses mesmos mapas teriam revelado um - a meu ver falso - "paradoxo", pois Fernando Henrique Cardoso obteve expressivas votações em São Paulo, o estado mais desenvolvido da federação, exatamente de acordo com os critérios utilizados por aqueles estudos. Ora, trata-se exatamente do peso do PSDB, de suas máquinas locais e de uma forma mais moderna de fazer política, ainda que incorpore fortemente perspectivas e aliados conservadores tradicionais. Incluindo, sobretudo, o Partido da Frente Liberal - PFL e o Partido Progressista Brasileiro - PPB, além do Partido Trabalhista Brasileiro - PTB, os partidos conservadores são marcados por baixos níveis de disciplina partidária, personalismo e clientelismo; a distorção do sistema representativo, no que tange à federação, permite que estejam sobre-representados na Câmara dos Deputados. Embora algumas mudanças nesse quadro possam estar em curso, esses partidos, definidos como conservadores por suas perspectivas ideológicas (principalmente por sua concepção autoritária de mundo e pelo neoliberalismo) e estilo político, claramente concentram-se nas regiões mais subdesenvolvidas, principalmente no Nordeste, e nos pequenos e mais pobres municípios; ademais, capturam um eleitorado mais velho, mais pobre e com nível de escolaridade mais baixo (Mainwaring et alii, 2000:13-14 e 58 e ss.). Ainda assim, nas eleições presidenciais atuais, de 2002, o próprio candidato do PT, Luiz Inácio Lula da Silva, teria, em princípio, conseguido penetrar inclusive nos pequenos municípios, os chamados "grotões" (municípios com menos de 20.000 habitantes, nos quais obteria, em sondagens de junho de 2002, 36\% dos votos), onde até há pouco o controle do voto se mostrava infenso à penetração de partidos de esquerda ${ }^{5}$, embora, é claro, convenha aguardar o resultado do pleito para que se possa fazer ilações mais fortes nesse sentido.

Tudo indica que nos deparamos crescentemente com dois fatores cruciais, para além tanto do controle do voto quanto da expressão individualizada de notáveis, os quais, sem esquemas burocráticos fortes, 
operavam de cima os partidos (como o Movimento Democrático Brasileiro - MDB, no período de oposição à ditadura militar): por um lado, com a independência do eleitorado e, por outro, com a importância, através do país como um todo, da implantação das máquinas partidárias. Estas funcionam nos moldes classicamente descritos por Weber (1988:324 e ss.) - isto é, como associações livres, burocratizadas e que buscam recursos financeiros para tomar parte em "batalhas" eleitorais mais ou menos livres também, sempre procurando recompensas pelos esforços nesta direção envidados -, o que não implica, ele frisa, falta de crença e de compromisso ideológico de seus quadros. No Brasil, hoje, isso se mostra, como de resto Weber já observara no que tange à social-democracia alemã do começo do século passado, de forma mais acentuada exatamente nos partidos mais à esquerda e mais democráticos. E tem lugar, em geral, com alcance "oligopólico" em termos da colonização do espaço político formal, possivelmente gerando os impasses que esse tipo de institucionalização implica no mundo contemporâneo (Santos, 1988, cap. 4). Isso não quer dizer que não seja possível o surgimento de "lideranças" que não se assentem sobre o sistema constituído de partidos, nem que o caráter altamente diferenciado do país não gere incongruências e fragilidades no que tange aos partidos. A despeito disso, e não obstante alguns lastimarem o que seria o baixo grau de institucionalização do sistema partidário brasileiro (Mainwaring, 2001), bem como independentemente de seu peculiar e elevado nível de fragmentação (Nicolau, 1996), creio ser evidente que, tudo somado, uma modernização acentuada da política patentemente encontra-se em curso, com suas vantagens e problemas, em estágio relativamente avançado e sem prejuízo de suas peculiaridades.

\section{QUAL MODERNIDADE?}

Isto posto, é possível então dizer que o Brasil adentrou a modernidade de forma definitiva. Ainda que a concentração da propriedade agrária permaneça em grande medida, as instituições brasileiras são muito semelhantes às dos países do centro do sistema global, com os quais compartilha a civilização moderna. Sua dinâmica é em muitos aspectos aproximada à deles, seja em termos de processos econômicos, tendências à juridificação, limites burocráticos do sistema político, mudança, na direção de um distanciamento, das identidades coletivas calcadas na pertença à classe operária, e daí por diante. Com 
isso, um autor chegou mesmo a sugerir que este "[...] novo contexto permite pensar a realidade brasileira como uma forma tão particular e específica como qualquer outra de enfrentar os problemas de integração social e os dilemas da construção democrática em sociedades capitalistas com economias cada vez mais globalizadas" (Sorj, 2000:123). Esta afirmação captura de modo acurado um aspecto crucial da evolução da sociedade brasileira nas últimas décadas, embora seu próprio autor se distancie de uma perspectiva que vê na globalização uma chave explicativa para toda e qualquer coisa. Evidentemente, contudo, o Brasil continua sendo um país específico e não haveria sentido em pensar a modernidade, mesmo em um país tão "ocidentalizado" como este, como se meramente estivesse em curso aqui uma repetição da modernidade européia ou norte-americana, como se, ainda que por caminhos tortos, chegássemos todos, no fim das contas, ao mesmo destino. Fernando Henrique Cardoso (2002:8), com indisfarçável referência aos processos políticos dos quais tem sido ele mesmo um dos principais protagonistas, pergunta-nos, ao rever a obra de Sérgio Buarque de Holanda, se não estaríamos assistindo à vitória de seus ideais, com o declínio das oligarquias, do caudilhismo personalista, do irracionalismo emocional do "homem cordial", com uma rejeição decidida do "passado agrarista e iberista". Talvez isso seja mesmo verdade, mas, mais uma vez, é bom qualificar essa afirmação, de modo a não sermos vítimas das armadilhas, hoje mais disfarçadas embora decerto ainda menos sofisticadas, de um tipo qualquer de teoria da modernização.

É sempre um pouco mais complicado pensar a modernidade entre nós, uma vez que nascemos com o próprio Ocidente e temos estado estreitamente vinculados à sua dinâmica, de forma dependente sem, entretanto, sermos de fato ocidentais (ver Domingues, 1992). A influência do Ocidente (se bem que compreendido de forma mais ampla que de costume, como logo veremos) é avassaladora, mas não há por que imaginar que nossas instituições e universo hermenêutico (cognitivo, normativo, expressivo e télico) são exatamente os mesmos que se encontram naquelas regiões. Um exemplo específico pode ajudar a situar melhor a questão.

Em uma análise já clássica, Santos propôs, há alguns anos, a tese de que encontramos no Brasil uma "dicotomia", um "híbrido institucional". Um dos elementos cruciais deste híbrido seriam as instituições da "poliarquia" (no sentido de Robert Dahl), que implicam "elevado 
grau de institucionalização da competição pelo poder (existência de regras claras, públicas e obedecidas) associado à extensa participação política, só limitada por requisito de idade", ao que subjazem os direitos clássicos democrático-liberais, a igualdade perante a lei e o controle da agenda pública (Santos, 1993:81). Ao lado dessas instituições poliárquicas, encontramos, todavia, um "hobbesianismo social poliforme", ensejando, na prática e em alto grau, a "recusa" às instituições poliárquicas, que não chegam, inclusive, a "alcançar extensão considerável do universo social brasileiro", em termos de segurança, proteção e previsibilidade (idem:89 e 93). Em lugar de retomar as análises de Santos no que toca ao sistema político, gostaria de sugerir uma outra via, a partir da qual creio ser possível avançar na direção de situar melhor a questão da modernidade brasileira.

Nas ciências sociais, assume-se, com freqüência e muito facilmente, que o mercado é, em tudo, semelhante ao que os autores da economia neoclássica supõem que ele seja. Isto é verdade inclusive no campo marxista, que apenas introduz como elementos adicionais em sua análise da questão a força de trabalho e a mais-valia, uma mercadoria preeminente e um tema politicamente explosivo. Em Habermas (1988:229 e ss., vol. 2), por exemplo, e aliás de forma condizente com sua inclinação em direção a uma teoria da modernização bastante tradicional, é precisamente essa a visão que encontramos: o que importa considerar é apenas a troca pontual entre agentes econômicos (sempre tomados como indivíduos, mesmo quando estes são empresas ou corporações), a partir de interesses discretos, que, por outro lado, proporcionam a "estabilização" de expectativas (isto é, equilíbrio na contingência) em uma economia funcionalmente diferenciada e balizada por ações instrumentais (ou, mais precisamente, "com propósito"). Com efeito, ele admite uma definição de normas que fornecem parâmetros ao mercado (ver, também, Habermas, 1968), mas deste está excluído absolutamente qualquer vestígio de "ação comunicativa". Com isso, formas específicas de organização da economia, inclusive capitalista, como as "redes" e, em especial, as hierarquias, bem como elementos cruciais, como a "confiança", são de todo excluídos de sua abordagem. Entretanto, é a eles que a sociologia econômica a partir dos anos 1990 vem dando grande atenção, o que leva a uma reavaliação bastante abrangente do que significa mercado, e pode e deve proporcionar uma visão muito mais sofisticada e particularizada de suas operações (ver Domingues, 1999a, cap. 6). Afinal, o mundo como 
um todo não pode ser reduzido aos padrões da economia neoclássica - aliás, nenhuma área dele pode, como os desastres recentes da "corporate America" vêm sobejamente evidenciando.

A economia capitalista possui instituições e configurações institucionais diversas, dependendo do país e/ou região onde se desenvolve. As regras que a regem, sua interpenetração com o Estado, as classes específicas em que se calca, as relações entre capital e trabalho, os padrões culturais com que se entrelaça, as motivações particulares que movem nela os diversos agentes, a escala das firmas (subjetividades coletivas) e a estrutura interna de cada uma delas, são elementos que devem ser sempre levados em conta ao analisarmos a economia ou o "mercado" em cada coordenada específica. Como entender, por exemplo, o capitalismo japonês sem atentar para a estrutura de clãs de sua economia? Ou a Rússia, cujos mercados são dominados por diversas "máfias"? Ou o Brasil, país onde as empresas familiares são ainda hegemônicas? Sobretudo, para voltarmos ao "híbrido" institucional brasileiro, como compreender o funcionamento de seu mercado, as regras que o regem, as motivações das pessoas, se em grande medida aquelas regulações decorrentes da poliarquia parecem não ser operativas em vastos setores do tecido social?

Naquele mesmo texto, Santos (1993:113-114) faz referência a pesquisas que indicam que a sociedade brasileira prima pela falta de confiança dos agentes uns nos outros, cristalizando-se, assim, uma "cultura cívica predatória". Em grande medida, esse parece ser o modelo de economia de mercado brasileira, no qual vigem a malfadada "lei de Gérson" e o que se costumava chamar de "capitalismo selvagem", termo que saiu de moda, mas não, infelizmente, da prática social. Ou seja, temos, em larga escala e em muitos âmbitos, uma economia capitalista não poliárquica, baseada em um individualismo que percebe o sujeito como exterior às normas e tende a operar à sua revelia. Isso resulta em uma competição mortífera e predatória, sem regras e, a rigor, de metas duvidosas, pois que tendem ao curto prazo. Isso implica, de resto, o que Machado de Assis há muito já assinalara como uma das características da concepção da competição entre nós, consubstanciada no sistema do "humanitismo", de Quincas Borba; nele, tamanha a predação mútua, sobrava ao vencedor nada mais que as batatas.

Mas isso seria tão-somente uma caracterização negativa, a qual a adição do conceito de "economia social hobbesiana" talvez não fosse ca- 
paz de por si superar. Na verdade, trata-se antes de perseguir projetos de pesquisa que nos dêem uma visão um pouco mais precisa do que se encontra em curso socialmente na economia brasileira - tema raramente abordado por nossa sociologia, porém extremamente em voga na sociologia sueca ou norte-americana ou mesmo francesa, como o patenteia o trabalho de Boltanski e Chiapello (1999). Afinal, que tipo de rede encontramos hoje no Brasil apropriada à complexificação do capitalismo contemporâneo que inclui, com certeza, interseções dos mundos poliárquico e não poliárquico? Isso no que se refere à dimensão cognitivo-analítica. Se nos voltarmos para a dimensão normativa, a questão da especificidade repõe-se. Poder-se-ia supor que meramente abraçar instituições poliárquicas resolveria o problema - que se trata, por exemplo, apenas de expandir os poderes e competências da justiça, como muitos parecem inclinados a crer? Ou não se trataria, ao contrário, de apostar no desenvolvimento de instituições societárias ou, talvez, sobretudo daquelas em que se encontrassem Estado e sociedade e se realizasse a mediação de conflitos, com o que um modelo mais específico de poliarquia poderia emergir?

Seria interessante considerar, nesse passo, mais uma vez a questão da passagem a uma ordem poliárquica no Brasil. Na verdade, mais que uma dinâmica social hobbesiana desbragada, o que possivelmente se divisa na sociedade brasileira hoje é a evolução unilateral da herança ibérica, tão importante na formação nacional. Antes de nos determos nela, quero, contudo, sublinhar que não se trata em absoluto de uma herança exclusiva e única, tampouco unívoca. Muitos outros elementos se misturaram na formação e ao longo da história do Brasil, oriundos de muitas fontes. Traços comunitários e expressivos, conformando diversos espaços de solidariedade e integração popular, foram incorporados e emergiram no curso desse processo. Lutas populares, defensivas, visando à preservação de espaços e modos de vida, por direitos ou por interesses instrumentais, têm contribuído para a manutenção ou o surgimento de "tradições" nacionais, cujas memórias são criativamente atualizadas no cotidiano de largas camadas da população, gerando e reproduzindo laços de solidariedade. A própria expansão colonial e a dinâmica do país após a Independência fizeram outras possibilidades irromperem. Doutrinas, formas de consciência e modos de comportamento são importados do Ocidente também desde há muito e acabaram por deitar raízes e conformar memórias que, ademais, evoluem ao longo dos séculos. Ainda assim, creio ser 
válido destacar essa herança ibérica dos inícios da modernidade européia e de nosso processo de colonização, cujas bases são neotomistas, as quais, ao vincularem-se à governação colonial da expansão portuguesa na América, impregnaram a formação nacional, com pesos variados de acordo com as diversas regiões do território, e coloriram inclusive as outras tradições que para aqui vêm confluindo.

Assim é que, originalmente, durante a colonização, um Estado integrativo e visto como responsável pelo bem comum se sobrepunha a um individualismo particular. Diferentemente daquele tipo de individualismo oriundo do protestantismo, que introjetava na consciência individual as normas sociais e tornava o sujeito responsável por elas, esse individualismo de fermentação ibérica percebia os sujeitos como livres perante as sociedades e suas normas, as quais, logo, não introjetavam, o mesmo ocorrendo com o sentido de responsabilidade moral, que se descarregava sobre o Estado, o qual, ele sim, fornecia parâmetros normativos aos indivíduos, que lidavam com eles de forma meramente cognitiva e, sobretudo, instrumental. A ordem, portanto, não é considerada como dependente de cada um, mas sim daquela subjetividade coletiva abrangente - o Estado. Os sujeitos individuais introjetam com certa leveza as sanções morais negativas, logo se comportam com facilidade ao arrepio da lei e inclusive de certos preceitos sociais básicos, cabendo ao Estado, como agente externo, operar nessa direção ${ }^{6}$.

O Império e a República, inclusive a referida tradição republicana, incorporaram essa herança, não obstante a articulação conceitual do problema se ter obscurecido ao desaparecerem os pilares explicitamente neotomistas em que esta se assentava no momento de sua gestação (Morse, 1982; Domingues, 1995a; 1997; Barboza Filho, 2000, esp. cap. 6:440-443). A "modernização conservadora" manteve-a em grande medida em seu horizonte, combinando-a com um tipo de patrimonialismo societário e esquemas de controle e subordinação pessoal baseados no "favor" (Franco, 1983), aliás, novamente tão bem retratados por Machado de Assis em várias ocasiões. A conjugação desses elementos permitia o controle das grandes massas rurais e das populações urbanas a princípio pouco numerosas e autônomas. À medida que a sociedade se complexificou, as crises sociais e políticas estalaram, com o corporativismo apresentando-se como mediação entre Estado e sociedade, tanto quanto forma de controle das cada vez mais numerosas massas urbanas, sobretudo daquelas incorporadas ao 
mercado formal de trabalho, ao passo que enormes parcelas dos "pobres" urbanos, marginalizados, eram de fato deixadas ao deus-dará.

Com essa crescente complexificação e o avanço dos processos de desencaixe, não só os mecanismos tradicionais de controle se mostraram incapazes de cumprir suas tarefas, mas também o projeto e as estratégias de incorporação ao estilo ibérico, pelo alto, se esgotaram. Tampouco esquemas baseados no "favor" puderam reproduzir-se. As massas tornaram-se, aos poucos, protagonistas crescentemente presentes da história do Brasil. O mesmo, contudo, não poderia ser dito da perspectiva individualista anômica, que era a outra face do binômio ibérico - esta longe de se esgotar ${ }^{7}$. Assim, é provavelmente de um híbrido semi-institucional que deveríamos em parte falar. Isso se desenha à medida que as instituições poliárquicas avançam, seguindo uma trajetória peculiar entre nós, como de resto por toda parte, sem que, em contrapartida, aquele tipo de individualismo encontre âncoras institucionais. Se o Estado era, enquanto entidade exterior aos indivíduos, e nesse sentido a qualquer noção de cidadania, o responsável único e exclusivo pela integração e pela solidariedade social, que instituições hoje poderiam cumprir esse papel, sem se restringir a promover interesses e solidariedades particularistas, porém sem se remeter direta e forçosamente ao Estado? Como tecer laços entre indivíduos que mantêm uma relação ambivalente com as instituições, aceitando-as como universais ao serem impostas de cima ou ao corresponderem a seus interesses particulares e circunstanciais, estando sempre prontos, contudo, a transgredir as regras sociais, se de seu interesse, e se não sofrerem sanções por parte dos poderes externos que garantem a ordem coletiva? Diagnósticos e soluções são sempre difíceis, arriscados e duvidosos. Mas aí me parece de fato radicar um problema crucial para o futuro da história do Brasil.

\section{PALAVRAS FINAIS}

Não deveria soar estranha a hipótese de que, na verdade, o Brasil é um país com certa dificuldade para criar instituições que favoreçam a solidariedade social. É evidente que o individualismo predatório engendra padrões regularizados de comportamento, calcados na falta de confiança e na imprevisibilidade das relações sociais. Nesse sentido, tem-se claramente um desenho institucional, o qual, aliás, se casa bem com a tendência à fragmentação social e a decadência de concepções de responsabilidade individual e estatal, pelo menos na Europa 
e nas Américas em geral. Instituições que substituam as ordens senhoriais e comunitárias populares "tradicionais", assim como a cidadania "regulada" da modernização conservadora, e proporcionem um mais alto grau de integração social e solidariedade têm sido de surgimento mais raro, principalmente no que concerne à espontaneidade da vida social sem interferência direta do Estado. Quando este é o caso e uma criatividade social voltada para a solidariedade e para a responsabilidade tem lugar, não devemos de modo algum desprezá-la como momento fundamental e instituinte inclusive da própria cidadania, desde que não se coagule em perspectivas exclusivistas e particularistas. A solidariedade e a integração social dependem de modo direto de muitas dessas instituições. Embora uma ação estatal mais sensível ao contexto e à dinâmica social também deva ser contemplada, essa valorização da capacidade criativa social mais ampla ajudaria provavelmente a superar a situação recorrente em que o Estado tanto se esforça por regular a vida social, tendo, contudo, que se contentar com resultados de baixa eficácia, porquanto suas regulamentações, amiúde, não corresponderem a uma dinâmica social mais consistente com suas pretensões normativas e legislativas (Santos, 1993:104). A solidariedade e a integração social não podem senão sofrer por conta disso.

Ora, enquanto imperou a modernização conservadora, isso não foi um grande problema. Por cima, a nova ordem, apesar dos arrivismos e malandragens, podia contar com uma dinâmica ainda em grande medida baseada no conhecimento direto, pois relativamente pouco diferenciada, sendo que os laços de família nela eram (como ainda em parte o são) preponderantes, inclusive talvez no que concerne a transações de maior monta. Por baixo, a exclusão para as margens dos grandes centros garantia certo controle dos setores populares e total indiferença em relação à dinâmica interna de seu mundo - no qual instituições específicas de regulamentação e controle ajudavam a fornecer parâmetros para a vida social (ver Sousa Santos (1995) para a legitimação da propriedade da terra nas áreas de favela). O mundo agrário tradicional respondia, por outro lado, pela sociabilidade e pelas regras que ordenavam as práticas de um vastíssimo contingente da população. Todavia, esse arranjo não tem mais como funcionar. $\mathrm{O}$ que, diga-se de passagem, o aumento da violência e da criminalidade parece atestar amplamente. Não quero dizer que não tem havido, ao longo da história republicana do Brasil, a criação de organizações de 
tipo variado - de interesses, como sindicatos e associações patronais, de voluntariado e opinião, ou de base popular comunitária. Tampouco se deve desconhecer o autoritarismo, amiúde brutal, do Estado durante a maior parte desse período. Porém, dificuldades e limites devem ser reconhecidos, sobretudo hoje, quando processos profundos de mudança social demandam novas identidades e novas formas de organização para que se logre um grau razoável de solidariedade e integração social.

Os processos de desencaixe e a profunda complexificação social do país, inclusive, mas não apenas, do ponto de vista econômico, com a diversificação e pluralização dos agentes, nem de longe admitem respostas tão simplistas e baseadas em instituições modernas "tradicionais" de cunho ocidental, isto é, aquelas que emergiram e tiveram vigência durante a maior parte do período moderno (sem prejuízo de uma possível refuncionalização, atual ou prospectiva, de algumas delas, que não dão conta da dinâmica social inclusive no solo social mesmo onde originalmente irromperam). Novas instituições são necessárias e devem, acredito, florescer no solo social, contando ou não com a mediação do Estado. De certa forma, mas com muitas especificidades, como as sugeridas acima, compartilhamos essa dinâmica e necessidade de criatividade social com os países do centro do sistema global moderno hoje. A radicalização da modernidade, em geral, vem criando problemas e demandando respostas inevitáveis e até certo ponto inadiáveis sobre aquilo que deveríamos chamar, creio, de terceira fase, de "articulação mista" da modernidade (Domingues, 2002, esp. caps. 9-11). Como cada país do sistema global lidará com a complexidade social que se aprofunda é algo que necessariamente variará, sem que se possa evitá-lo, entretanto. Se desconhecer a modernidade do Brasil contemporâneo e o sucesso que coletivamente logramos em nossos projetos conflituosos de modernização seria um grande erro, a adesão às noções implícitas nas teorias tradicionais da modernização - que proporcionam uma imagem chapada do desenvolvimento histórico, que teria apenas uma via, direção e ponto de chegada, estejam agentes incluídos (de maneira subordinada) ou não nessa pintura - pouco nos ajuda a resolver a questão. Decerto, as variações do desenvolvimento histórico dependem das "rotas dependentes" que derivam das "escolhas" que indivíduos e coletividades têm de fazer, estejam ou não cientes disso. Heranças e memórias condicio- 
nam, contudo, como isso ocorre e que respostas são vislumbradas perante cada encruzilhada do cotidiano e da história.

Mais imaginação institucional será requerida tanto do Estado quanto da sociedade brasileira no futuro próximo, uma vez que continuamos a sofrer dos problemas da falta de modernização em certos campos, mas também daqueles que derivam da própria modernidade, a qual se instalou definitivamente entre nós. Como compatibilizar a liberdade com a igualdade e, sobretudo, com a solidariedade e a responsabilidade em uma sociedade complexa, de instituições deficitárias - e muita desigualdade social -, põe-se como um dos grandes desafios que o Brasil encontrará em sua história futura imediata. Que projetos, conflitos e lutas sociais poderão levar nessa direção é algo ainda em aberto, e que pode assumir múltiplas e variadas formas e perspectivas.

(Recebido para publicação em setembro de 2002)

\section{Pós-Escrito}

Este artigo foi redigido entre julho e agosto de 2002, antes, portanto, do primeiro turno das eleições deste ano. Os resultados destas confirmam, a meu ver, plenamente as principais teses nele expostas. Quaisquer que sejam os problemas e rumos do país daqui para a frente, parece agora definitivamente claro que iniciamos uma nova fase da história do Brasil. 


\section{NOTAS}

1. Ver Velho (1975), que discute exatamente o fechamento e o controle da fronteira, e põe o caso brasileiro em uma perspectiva comparada.

2. Ao longo deste texto, de acordo com a tradição sociológica, irei referir-me a instituições como modos regulares de interação social, os quais podem assumir, ou não, feição formal (ver Domingues, 1995b:143).

3. Não quero aqui, de qualquer forma, entrar no debate acerca da viabilidade ou não de modelos futuros de agricultura familiar no Brasil, uma vez que não se relaciona diretamente com o tema deste ensaio.

4. Fonte: Brasil em Síntese, Instituto Brasileiro de Geografia e Estatística, Censo Agropecuário (1995/1996). Levantamento Sistemático da Produção Agrícola. Pesquisa Pecuária Municipal (www.ibge.gov.br). Devo assinalar, contudo, que arrisco aqui a apresentação desses dados, extraindo-os diretamente das informações resumidas do IBGE, porque os especialistas no assunto infelizmente não apresentam, no curso de suas discussões e polêmicas, dados sintéticos e amplos que pesquisadores que não trabalham diretamente nesse campo de estudos possam utilizar com confiança e certeza de sua validade.

5. Segundo dados da pesquisa IBOPE/CNI de 12/6/2002 a 16/6/2002 (Fonte: O Globo, 1/6/2002).

6. Do ponto de vista de uma sociologia weberiana das formas de consciência, poder-se-ia sugerir que ao Estado ficava reservado um ativismo zeloso da integração social; no caso do indivíduo, perante a sociedade como um todo, era meramente a acomodação que se demandava e ele mesmo aceitava e visava como norma de comportamento, ao passo que, no que tange à sua vida pessoal, um ativismo forte, porém não ascético, voltado para o avanço de seus próprios fins, organizava as perspectivas de vida e ação. A República em particular, mas em parte já o Império, introduziram o "progresso" como o horizonte ao qual deveria ser dirigido o ativismo do Estado. Várias concepções de mundo e formas de luta populares transplantaram o ativismo, contudo, da esfera do Estado para outras subjetividades coletivas, como sindicatos e associações de cunho variado, o mesmo acontecendo por vezes com projetos e entidades burguesas e de classe média. Para a formulação geral do "ativismo" e da "acomodação", ver Weber (1920).

7. Outras formas de individualismo, inseridas no que, em linguagem habermasiana, se poderia designar como outros "mundos da vida", como as que se encontram em certas vertentes das religiões afro-brasileiras, parecem adotar perspectiva semelhante no que tange à organização da vida social poliárquica. Por outro lado, a vida comunitária evangélica parece responder por sentimentos de comunidade e de solidariedade também fortemente presentes em vastos setores da população, em formas modernizadas e não incompatíveis com valores individualistas e voltados para a promoção da autonomia do sujeito, já para não falar do aumento do pluralismo e da escolha religiosa como representando mais liberdade, que advém exatamente dos referidos processos de desencaixe. 


\section{REFERÊNCIAS BIBLIOGRÁFICAS}

BARBOZA FILHO, Rubem. (2000), Tradição e Artifício. Iberismo e Barroco na Formação Americana. Belo Horizonte, Editora UFMG.

BOLTANSKI, Luc e CHIAPELLO, Ève. (1999), Le Nouvel Sprit du Capitalisme. Paris, Gallimard.

CARDOSO, Fernando Henrique. (2002), "Sérgio, um Jovem Eterno". O Globo, Segundo Caderno, 14 de julho.

DELGADO, Guilherme C. (2001), "Expansão e Modernização do Setor Agropecuário no Pós-Guerra: Um Estudo da Reflexão Agrária". Estudos Avançados, no 43.

DOMINGUES, José Maurício. (1992), “A América. Intelectuais, Interpretações e Identidades". Dados, vol. 35, nำ2, pp. 267-289.

. (1995a), "Richard Morse and the 'Iberian-American Path'". Revista Interamericana de Bibliografia, vol. 45.

(1995b), Sociological Theory and Collective Subjectivity. London/New York, Saint Martin's Press/Macmillan.

. (1997), “Imaginário Social e Esfera Pública no Rio de Janeiro dos Anos 30". Arché, no 18 .

(1999a), Criatividade Social, Subjetividade Coletiva e a Modernidade Brasileira Contemporânea. Rio de Janeiro, Contra Capa.

(1999b), Sociologia e Modernidade. Para Entender a Sociedade Contemporânea. Rio de Janeiro, Civilização Brasileira.

. (2002), Interpretando a Modernidade. Imaginário e Instituições. Rio de Janeiro, Fundação Getulio Vargas Editora.

FRANCO, Maria Sylvia de Carvalho. (1983) [1969], Homens Livres na Ordem Escravocrata. São Paulo, Kairós.

GARCIA, Afrânio e PALMEIRA, Moacir. (2001), “Rastros de Casas Grandes e Senzalas: Transformações Sociais no Mundo Rural Brasileiro", in I. Sachs, J. Witheim e P. S. Pinheiro (orgs.), Brasil: Um Século de Transformações. São Paulo, Companhia das Letras.

GRAZIANO DA SILVA, José. (2001), "Velhos e Novos Mitos do Rural Brasileiro". Estudos Avançados, no 43.

HABERMAS, Jürgen. (1968), “Technik und Wissenschaft als Ideologie”, in Technik und Wissenschaft als Ideologie. Frankfurt am Main, Suhrkamp.

. (1988) [1981], Theorie des Kommunikativen Handelns. Frankfurt am Main, Suhrkamp, vols. 1 e 2.

LEAL, Victor Nunes. (1976) [1948], Coronelismo, Enxada e Voto. São Paulo, Alfa-Ômega.

MAINWARING, Scott. (2001), Sistemas Partidários em Novas Democracias. O Caso do Brasil. Rio de Janeiro/Porto Alegre, Fundação Getulio Vargas Editora/Mercado Aberto. 


\section{A Dialética da Modernização Conservadora e a Nova História do Brasil}

_. MENEGUELLO, Rachel e POWER, Timoty. (2000), Partidos Conservadores no Brasil Contemporâneo. São Paulo, Paz e Terra.

MOORE JR., Barrington. (1966), Social Origins of Dictatorship and Democracy: Lord and Peasant in the Making of the Modern World. Hardmondsworth, Penguin.

MORSE, Richard. (1982), El Espejo de Próspero. México, Siglo XXI.

NAVARRO, Zander. (2002a), "'Mobilização sem Emancipação' - As Lutas Sociais dos Sem-Terra no Brasil", in B. Sousa Santos (org.), Produzir para Viver. Os Caminhos da Produção Não Capitalista. Rio de Janeiro, Civilização Brasileira.

. (2002b), “O MST e a Canonização da Ação Coletiva (resposta a Horácio Martins Carvalho)", in B. Sousa Santos (org.), Produzir para Viver. Os Caminhos da Produção Não Capitalista. Rio de Janeiro, Civilização Brasileira.

NICOLAU, Jairo M. (1996), Multipartidarismo e Democracia. Rio de Janeiro, Fundação Getulio Vargas Editora.

REIS, Elisa P. (1982), "Elites Agrárias, State-Building e Autoritarismo". Dados, vol. 25, no 3, pp. 331-348.

ROMERO, César et alii. (2000), “As Eleições Presidenciais no Brasil Pós-Ditadura Militar: Continuidade e Mudança na Geografia Eleitoral”. Alceu, vol. 1, Rio de Janeiro.

SANTOS, Wanderley Guilherme dos. (1979), Cidadania e Justiça. Rio de Janeiro, Campus.

(1988), Paradoxos do Liberalismo. Rio de Janeiro/São Paulo, IUPERJ/Vértice.

(1993) [1992], Razões da Desordem. Rio de Janeiro, Rocco.

SOARES, Gláucio Ary Dillon. (2001), A Democracia Interrompida. Rio de Janeiro, Fundação Getulio Vargas Editora.

SORJ, Bernardo. (2000), A Nova Sociedade Brasileira. Rio de Janeiro, Zahar.

SOUSASANTOS, Boaventura. (1995), Toward a New Common Sense. New York, Routledge.

VEIGA, José Eli. (2001), “O Brasil Rural ainda Não Encontrou seu Eixo de Desenvolvimento". Estudos Avançados, no 43.

VELHO, Otávio. (1975), Capitalismo Autoritário e Campesinato. São Paulo/Rio de Janeiro, Difel.

WEBER, Max. (1920) [1915-1919], Die Wirtschafsethik der Weltreligionen, in Gesammelte Aufsätze zur Religionssoziologie I. Tübingen, J. C. B. Mohr (Paul Siebeck).

. (1988) [1918], “Parlament und Regierung im neugeordneten Deutschland", in Gesammelte politische Schriften. Tübingen, J. C. B. Mohr (Paul Siebeck).

WERNECK VIANNA, Luiz. (1976), Liberalismo e Sindicato no Brasil. Rio de Janeiro, Paz e Terra.

. (1991), De um Plano Collor a Outro. Rio de Janeiro, Revan.

. (1996), “Caminhos e Descaminhos da Revolução Passiva à Brasileira”. Dados, vol. 39 , no 3, pp. 377-392. 


\section{ABSTRACT}

\section{Conservative Modernization Dialectics and the New Brazilian History}

In this article, we propose that the so-called "conservative modernization" has been completed in Brazil. Dialectically, success led to overcoming both the conservative modernization itself and the "regulated order" before a new integrative institutional frame could be fully developed. In advancing this argument, we review the recent literature on the agrarian issue and the political-institutional evolution of Brazil, in addition to an overall perspective of the theory of modernization and citizenship. Furthermore, we propose that there is no reason to imagine the prevalence of a homogenous modernity, which would only reproduce in Brazil what can be found elsewhere. Consequently, we propound that, in contemporary Brazil, we find a specific modernity in which stands out the neo-thomist tradition of the country.

Keywords: conservative modernization; polyarchy; neo-thomism

\section{RÉSUMÉ}

La Dialectique de la Modernisation Conservatrice et la Nouvelle Histoire du Brésil

Cet article présente l'hypothèse selon laquelle ce qu'on a convenu d'appeler "modernisation conservatrice" au Brésil est achevée. Son succès a amené dialectiquement à son dépassement ainsi qu'à celui de "l'ordre réglé", sans pour autant qu'un nouveau cadre institutionnel intégrateur se soit complété. On fait appel pour argumenter cette thèse à la littérature récente sur la question agraire et l'évolution polico-institutionnelle du pays, ainsi qu'une perspective générale de la théorie de la modernisation et de la citoyenneté. L'article argumente par ailleurs que cependant il n'y a pas de raison pour supposer une modernisation homogène, qui ne ferait que reproduire au Brésil ce qui se trouve dans d'autres territoires. On argumente donc à partir de la spécificité de la modernité du Brésil contemporain, notamment la tradition néothomiste du pays.

Mots-clé: modernisation conservatrice; poliarquie; néothomisme 